\title{
Las funciones del derecho penal y de la justicia transicional en la jurisdicción especial para la paz
}

The Functions of the Criminal Law and the Transitional Justice in the Special Jurisdiction for Peace

\author{
Carlos Guillermo Castro Cuenca ${ }^{\text {a }}$ \\ Universidad del Rosario, Colombia \\ guillermocastrocuenca@hotmail.com \\ ORCID: https://orcid.org/0000-0001-9238-9049
}

DOI: https://doi.org/10.11144/Javeriana.vj69.fdpj

Fecha de recepción: 23 Octubre 2019

Fecha de aprobación: 23 Noviembre 2019

Fecha de publicación: 30 Junio 2020

\section{Resumen:}

Este artículo analiza cómo las instituciones del Derecho penal pueden ayudar a la Jurisdicción Especial para la Paz a cumplir los objetivos esenciales de la Justicia Transicional como: promover la justicia y el esclarecimiento de violaciones a los derechos humanos, contribuir al fortalecimiento del Estado de Derecho y alcanzar la reconciliación. Concretamente, este artículo aborda tres instituciones que pueden permitir al sistema alcanzar este difícil reto: el régimen de condicionalidad, las sanciones especiales y el sistema de mayor y menor responsabilidad. Estas herramientas permiten que ex combatientes, miembros de la fuerza pública y agentes estatales no militares y civiles, contribuyan a la verdad, a la reparación de las víctimas, a la no repetición de los crímenes y participen en los procesos so pena de perder los tratamientos penales especiales o incluso ser expulsados del sistema.

Palabras clave: derecho penal, justicia transicional, derecho penal internacional, víctimas, justicia, verdad, reparación y no repetición.

\begin{abstract}
:
This article analyzes how the Criminal Law Institutions can help the Special Jurisdiction for Peace to fulfill the main objectives of the Transitional Justice i.e., to promote justice and accountability for human rights violations, contribute to strengthening the rule of law and reach reconciliation. In particular, this article studies three institutions that can allow the system to achieve this complex challenge: the conditionality regime, the special sanctions, and the system of most and less responsibility. These tools allow excombatants, Members of the public security, non-military state agents and civilians, to contribute to the truth and reparation of the victims, not to repeat their crimes, and to participate in the processes, under penalty of losing special criminal law treatments and even being ejected from the system.
\end{abstract}

Keywords: criminal law, transitional justice, international criminal law, victims, justice, truth, reparation, no repetition.

\section{Introducción}

La justicia transicional está compuesta por un conjunto de medidas especiales de naturaleza histórica, reparadora, penal, administrativa y constitucional que busca alcanzar una transición pacífica ${ }^{[1]}$. Dentro de estos instrumentos, el Derecho penal tiene un papel importante con el objetivo esencial de superar una situación de abusos masivos o graves violaciones a los derechos humanos ocasionados por situaciones que afectan a toda la población ${ }^{[2]}$.

En todo caso, debe tenerse en cuenta que, más allá de la retribución, en un contexto transicional los procesos penales tienen como objetivos trazar la línea entre el anterior y el nuevo régimen y condenar la violencia del pasado, distinguen lo justo de lo injusto y expresan la deslegitimación de los crímenes perpetrados ${ }^{[3]}$. En este sentido, el Derecho penal en los procesos de justicia transicional desempeña un papel esencial en el

Notas de autor

a Autor de correspondencia. Correo electrónico: guillermocastrocuenca@hotmail.com 
reconocimiento y la estigmatización del mal (wrongdoing) como un requisito esencial de toda sociedad en un proceso de transformación ${ }^{[4]}$.

Por lo anterior, la justicia penal transicional se diferencia de la justicia penal ordinaria por su carácter más reparador y restaurativo, pues es parte de un sistema que debe servir a la reconciliación nacional, la reparación de las víctimas y la reconstrucción de lo ocurrido en los años de conflicto ${ }^{[5]}$.

En este marco, surge la justicia con enfoque amplio contemplado en el artículo $1^{\circ}$ de la Ley 1922 de 2018 cuyas finalidades están estrechamente relacionadas con las funciones de la pena: (i) asegurar la reconciliación y el establecimiento de una paz estable y duradera, (ii) salvaguardar el principio de legalidad y (iii) procurar la restauración del daño causado y la reparación de las victimas afectadas por el conflicto armado, las garantías de no repetición y el esclarecimiento de la verdad de los hechos ${ }^{[6]}$. En virtud de lo anterior, este artículo tiene por objeto señalar algunos criterios sobre la forma como se cumplen las funciones del Derecho penal y de la justicia transicional en la Jurisdicción Especial para la Paz (en adelante JEP).

\section{Objetivos de la justicia transicional}

El modelo de justicia transicional de la JEP tiene unos objetivos que, si bien no tienen un enfoque netamente penal, sí se encuentran muy relacionados con éste:

\section{Alcanzar una transición que asegure la reconciliación y el establecimiento de la paz}

La primera característica de la justicia transicional proviene de su propia denominación: se aplica a sociedades en transición ${ }^{[7]}$ y tiene por objeto la consolidación de la democracia ${ }^{[8]}$ para superar abusos masivos o graves violaciones a los derechos humanos que afecten a toda la población ${ }^{[9]}$.

De esta manera, la transición abarca eventos de conflicto armado como el colombiano que han creado una situación de anormalidad jurídica, social y política que deben ser superados a través de la justicia transicional. Por ello, el artículo $1^{\circ}$ de la Ley 1922 de 2018 señala que dentro de las finalidades de la justicia se encuentra "garantizar los presupuestos necesarios para asegurar la reconciliación y el establecimiento de una paz estable y duradera" ${ }^{[10]}$.

Cuando la justicia transicional se aplica a un conflicto armado su objetivo primordial es solucionar las fuertes tensiones que se presentan entre la justicia y la paz, entre los imperativos jurídicos de satisfacción de los derechos de las víctimas y las necesidades de lograr el cese de hostilidades ${ }^{[11]}$. Para ello es necesario lograr un equilibrio entre ponerle fin a las hostilidades y prevenir la vuelta a la violencia (paz negativa) y consolidar la paz mediante reformas estructurales y políticas incluyentes (paz positiva) ${ }^{[12]}$.

En este marco, la justicia para el posconflicto debe estar dirigida "al fin de la guerra interna y alcanzar paz para todos los combatientes, sobre la base de la reconciliación de todos los actores, para garantizar la no repetición" ${ }^{[13]}$. Para desarrollar estas finalidades la justicia ordinaria es insuficiente pues: (i) la violencia en el estado de guerra no puede ser valorada ni calificada con el criterio penal que regularmente aplica y (ii) para alcanzar la paz no se puede tratar a los combatientes como criminales ordinarios, salvo que se hayan presentado crímenes de guerra o crímenes de lesa humanidad. Estos últimos delitos son el límite ratione materia de la justicia transicional, al que se suma otro límite de carácter subjetivo, en virtud del cual tradicionalmente solo se somete a esta justicia a los máximos responsables ${ }^{[14]}$.

Para cumplir con este objetivo, la JEP cuenta con un importante instrumento para garantizar que los comparecientes no incurran en nuevos delitos como es el régimen de condicionalidad, el cual exige que los comparecientes cumplan obligaciones específicas frente a la verdad, la justicia, la reparación y la no 
repetición ${ }^{[15]}$. En este sentido, si se verifica en un incidente de incumplimiento que la persona ha incurrido en nuevos delitos puede ser juzgado por la justicia ordinaria y perder los beneficios del sistema ${ }^{[16]}$ y si se establece que se ha alzado nuevamente en armas puede ser excluido del sistema ${ }^{[17]}$.

\section{El objetivo de tratar con el pasado}

La segunda característica de la justicia transicional es que tiene por objeto tratar con el pasado (deal with the past $)^{[18]}$. En este sentido, no solamente es importante establecer responsabilidades individuales, sino también enjuiciar el mal en sí mismo (wrongdoing). La importancia de los procesos penales no gira solo en torno al derecho a la justicia de las víctimas, sino que los juicios en la transición trazan la línea entre el anterior y el nuevo régimen y condenan la violencia del pasado, distinguen lo justo de lo injusto y expresan la deslegitimación de los crímenes perpetrados, lo cual resulta fundamental para la consolidación de una nueva democracia y la construcción de un nuevo orden legal ${ }^{[19]}$.

En este sentido, el Derecho penal en los procesos de justicia transicional desempeña un papel esencial en el reconocimiento y la estigmatización del mal (wrongdoing) como un requisito esencial de toda sociedad en un proceso de transformación ${ }^{[20]}$. Este mal estigmatizado no se refiere a situaciones aisladas, sino a eventos masivos que afectan a gran parte de la población. Se trata de un mal generalizado, tal como lo han denominado Nino y Malamud-Goti, el cual tiene efectos concretos en la mente, la libertad y los derechos de los individuos, incluyendo, por supuesto, a quienes cometen crímenes internacionales quienes, en muchos casos, son víctimas ( por ejemplo, de reclutamiento forzado) y en otros aplican reglas propias de una subcultura arraigada profundamente en la sociedad.

Por ello, la realización de un recuento histórico oficial, Official Historical Account, es fundamental para toda transición ${ }^{[21]}$. La verdad permite reconocer el sufrimiento de las víctimas y garantizar la futura coexistencia al superar los hechos ocurridos ${ }^{[22]}$. La justicia histórica es un mecanismo para responder al gran desafío que las graves violaciones causan a la memoria: el traumatismo de una repetición que se alimenta a sí misma, pues los hechos constituyen heridas de la memoria que se reabren constantemente y difícilmente pueden sanar en forma autónoma ${ }^{[23]}$.

Para Ferrajoli, a efectos de conciliar equilibradamente entre justicia y paz, debe realizarse un juicio histórico de manera pública ${ }^{[24]}$. Asimismo, para garantizar la no repetición, es necesario construir memoria colectiva de lo ocurrido; en los procesos se debe comprobar la verdad y descubrir a los responsables ${ }^{[25]}$. Todas las víctimas tienen el derecho a conocer lo que ocurrió, quién fue el autor del crimen, las circunstancias de tiempo, modo y lugar, y conocer si es un crimen de guerra o de lesa humanidad. La familia también tiene el derecho a conocer lo sucedido con los desaparecidos. En materia psicosocial, ayuda a superar heridas, evitar la negación y el terror, para garantizar la no repetición ${ }^{[26]}$.

Esta finalidad está relacionada con el objetivo de alcanzar la verdad que se encuentra contemplado desde el primer artículo de la Ley 1922 de 2018 en el "esclarecimiento de la verdad de los hechos" 27] como consecuencia de la justicia restaurativa, pero además tiene una consecuencia directa en los objetivos de la investigación al interior de la JEP que tiene objetivos concentrados en la obtención de una verdad integral de lo sucedido:

1. Determinar las circunstancias geográficas, económicas, sociales, políticas y culturales en las cuales sucedieron los delitos de competencia de la JEP.

2. Cuando proceda describir la estructura y el funcionamiento de la organización criminal, sus redes de apoyo, las características del ataque y los patrones macrocriminales.

3. Develar el plan criminal. 
4. Asociar casos y situaciones.

5. Identificar sus responsables.

6. Establecer los crímenes más graves y representativos.

7. Identificar a las víctimas y las condiciones particulares que les ocasionen afectaciones diferenciadas

8. Cuando sea procedente, determinar los móviles del plan criminal y en especial aquellos que comporten razones de discriminación por etnia, raza, género, orientación sexual, identidad de género, convicciones religión, ideologías políticas o similares.

9. Establecer las rutas del narcotráfico y actividades ilícitas; bienes de los perpetradores y las organizaciones criminales ${ }^{[28]}$.

En virtud de lo anterior, el Sistema Integral de Verdad, Justicia, Reparación y no Repetición no tiene por objeto el esclarecimiento de hechos aislados, sino la obtención de la verdad a través de macrocasos, siguiendo el modelo señalado desde el Marco Jurídico para la Paz y luego reiterado en el Acto Legislativo 01 de 2017 y en las Sentencias C-579 de 2013 y C-080 de 2018.

Para lograr este objetivo, la JEP cuenta con mecanismos muy importantes, no solo en materia de investigación criminal, sino también a través de instrumentos que garantizan la revelación de verdad plena por los comparecientes: (i) la existencia de un régimen punitivo que depende del reconocimiento de la verdad, en virtud del cual se puede ser objeto de penas de hasta 20 años de prisión si no se reconoce un delito efectivamente cometido y se puede recibir sanciones sin prisión intramural si se admite responsabilidad de manera temprana, (ii) la posibilidad de iniciar un incidente de incumplimiento del régimen de condicionalidad si no se aporta verdad plena, lo cual podría implicar la pérdida de beneficios como la libertad condicionada ${ }^{[29]}$ y (iii) el establecimiento de un sistema especial para quienes no sean máximos responsables que pueda facilitar la delación de las personas que no tengan una participación esencial en la estructura del grupo.

\section{Alcanzar la justicia}

La justicia transicional es ante todo justicia. No tiene un contenido netamente simbólico o filosófico, pues implica consecuencias concretas para los individuos y por ello debe ser justa, formal y materialmente. Por ello, su construcción se ha realizado a través del análisis comparativo de las consecuencias del mal (wrongdoing) en sociedades en transición y no simplemente con análisis teóricos o políticos.

En virtud de lo anterior, es esencial respetar el debido proceso $^{[30]}$ y sus garantías esenciales, en especial las siguientes ${ }^{[31]}$ : procesos adversariales y públicos; derecho a escoger un abogado; derecho a apelar; no retroactividad; respeto a las limitaciones legales; responsabilidad individual; presunción de inocencia; plazo razonable; deliberación suficiente. La aplicación del Derecho penal y en especial de la pena, exige unos presupuestos mínimos de legitimidad y soberanía y por ello la afectación de ambas en un Estado, bien sea por la existencia de una dictadura o por la ausencia de control institucional, podría llegar a tener una incidencia en la determinación de responsabilidades ${ }^{[32]}$.

$\mathrm{Al}$ respecto, Fornasari expone claramente el principal peligro frente a las garantías que surgen de los contextos transicionales: la transformación del Derecho penal como una Carta Magna del delincuente a la Carta Magna de la Victima es peligrosa, pues convierte al derecho penal moderno en un derecho penal de la venganza, lo cual puede incluso transformarlo en un Derecho penal de los vencedores o del enemigo. Por ello se hace necesario entender que las garantías básicas del derecho penal frente a los procesados son innegociables ${ }^{[33]}$.

Para cumplir con este objetivo, la Ley 1922 de 2018 establece numerosos mecanismos para salvaguardar el debido proceso y otorgar legitimidad al sistema: (i) la salvaguarda de los principios prohomine ${ }^{[34]}$, debido 
proceso $^{[35]}$ y presunción de inocencia ${ }^{[36]}$ contemplados en su artículo $1 .^{\circ}$; (ii) el establecimiento de un proceso respetuoso del debido proceso y el derecho de defensa en las modalidades adversarial ${ }^{[37]}$ y de reconocimiento de verdad y responsabilidad ${ }^{[38]}$; (iii) la consagración de un sistema de recursos de reposición ${ }^{[39]}$ y apelación ${ }^{[40]}$ $y_{\text {queja }}{ }^{[41]}$ y (iv) el establecimiento de un régimen probatorio que respete las garantías ${ }^{[42]}$.

\section{PARTE 3: Las funciones de la pena y del Derecho penal en la justicia transicional}

Los problemas que tiene la aplicación de las funciones de la pena respecto de países que sufren conflictos armados internos dejan también lecciones para los procesos de justicia transicional, en particular en relación con las características especiales que deberá tener el cumplimiento de las funciones de la pena.

\section{La prevención especial negativa}

La prevención especial negativa señala que la pena tiene como misión impedir que el delincuente cometa nuevos crímenes contra la sociedad ${ }^{[43]}$. La prevención especial negativa está directamente relacionada con una de las finalidades esenciales de la justicia transicional: la garantía de no repetición de los crímenes ${ }^{[44]}$, pues uno de los objetivos esenciales del proceso de transición es prevenir que se sigan cometiendo delitos contra la población. En este aspecto, es fundamental que el proceso garantice una real desarticulación de los grupos al margen de la ley y de sus actividades ilícitas, ya que, de lo contrario, continuarán cometiendo crímenes masivos contra la población o se transformarán en otros nuevos con distinto nombre, pero con similares objetivos.

Para cumplir con esta finalidad la JEP no cuenta con el instrumento de privación de la libertad, pero sí con dos medidas muy importantes: (i) si la persona comete nuevos delitos (después del $1^{\circ}$ de diciembre de 2016) queda sujeto a la justicia ordinaria ${ }^{[45]}$ y por ello podría perder inmediatamente la libertad y (ii) al interior de la JEP puede perder los beneficios del sistema en un incidente de incumplimiento del régimen de condicionalidad $^{[46]}$.

En contextos de justicia transicional, una medida muy conocida de prevención especial negativa es la lustración, que implica sacar de la función pública a personas involucradas en graves violaciones a los derechos humanos $^{[47]}$. Sin embargo, es necesario evitar que se utilice para exclusiones con motivaciones políticas. Para el caso del sistema de la JEP debe tenerse en cuenta que si bien el Acto Legislativo 01 de 2017 habilitó la participación en política, la Sentencia de la Corte Constitucional C-674 de 2017 realizó una serie de consideraciones especiales sobre el alcance de la sujeción de la reincorporación a la vida pública al sistema de condicionalidades: (i) las personas que no contribuyan a la consecución de los objetivos del sistema no pueden acceder a la habilitación prevista; (ii) estas personas pueden perderla si incumplen las condiciones del sistema; (iii) las personas a las que se les impongan las sanciones ordinarias no podrán ser destinatarias de la habilitación prevista; (iv) aunque la habilitación para participar en política y para ejercer los demás derechos de participación política en principio comprende a las personas que han sido sancionadas por la justicia ordinaria, por vía de la suspensión de la condena prevista en el parágrafo del artículo transitorio 20, dicha suspensión de inhabilidades también se encuentra condicionada al cumplimiento progresivo y de buena fe de las obligaciones del sistema; (v) los miembros de las FARC, para efectos de la inscripción de sus candidatos, corresponderá al Alto Comisionado para la Paz certificar acerca de la pertenencia de las FARC, y al Secretario Ejecutivo de la JEP, sobre el compromiso de sometimiento al sistema y; (vi) corresponde a la JEP verificar el cumplimiento del sistema de condicionalidades. 


\section{La prevención especial positiva}

La prevención especial positiva señala, por su parte, que la función de la pena es la reintegración del individuo a la sociedad ${ }^{[48]}$, también llamada resocialización, cuyo cumplimiento es especialmente difícil en sociedades en las cuales el crimen tiene más incentivos que obstáculos. La teoría de la elección racional señala que los delincuentes buscan obtener beneficios de su conducta criminal, situación que envuelve la adopción de decisiones y de elecciones racionales ${ }^{[49]}$. Sin embargo, la decisión de cometer un crimen específico no solamente depende de las necesidades del sujeto, sino también del contexto situacional y de la información disponible sobre este.

En todo caso, la rehabilitación no puede verse como un simple tratamiento, también debe incluir un componente de reeducación ocupacional que permita, después de cumplir la pena, que los victimarios puedan ser integrados en redes de ayuda que les ayude, entre otras cosas, a encontrar trabajo y vivienda, lo cual es por sí mismo bastante difícil ${ }^{[50]}$.

El individuo tiene en cuenta los beneficios esperados de su comportamiento criminal y no criminal y si cometer un crimen tiene mayor utilidad que no cometerlo - lo cual implica que existe un riesgo aceptable de ser capturado, menor que la cantidad que estima ganar-, el sujeto se decidirá a favor de cometer el delito ${ }^{[51]}$. Como en el conflicto armado la criminalidad es organizada y económica, la rentabilidad es muy alta y por ello la reincidencia también. La prisión se convierte muchas veces solamente en una universidad del delito en la cual la persona que comete un delito potencia sus habilidades criminales.

Para cumplir con esta finalidad la JEP relaciona directamente la resocialización con el cumplimiento de las penas alternativas, exigiendo el compromiso para su aplicación:

Para tener derecho a la pena alternativa se requerirá que el destinatario se comprometa a contribuir con su resocialización a través del trabajo, capacitación o estudio durante el tiempo que permanezca privado de la libertad, y en su caso a promover actividades orientadas a la no repetición ${ }^{[52]}$.

\section{Prevención general negativa}

La prevención general desempeña un papel en la justicia transicional, pues a través de juicios y condenas se busca evitar que se cometan nuevos crímenes o se generen nuevas guerras. A este respecto se pueden recordar las palabras del juez Robert Jackson durante los juicios de Núremberg, quien señalaba que era necesario "hacer la guerra menos atractiva para aquellos quienes tienen los gobiernos y los destinos de la gente en

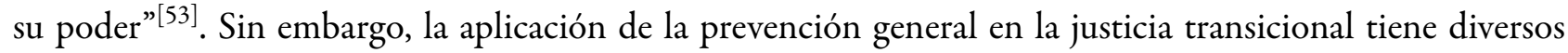
problemas: (i) difícilmente el precedente de castigo severo en un país pueda aplicarse de manera automática en otro completamente diferente; (ii) las situaciones de turbulencia o fragilidad que se presentan en contextos de justicia transicional hacen que estos precedentes sean considerados sólo marginalmente por los gobernantes; (iii) el efecto preventivo en estos casos es disminuido por los excesivos beneficios temporales obtenidos por quienes abusan del poder, como los dictadores; y (iv) las personas que dirigen la comisión masiva de estos crímenes, en muchas ocasiones, se ven como parte de una cruzada contra determinadas situaciones sociales que afectan su razonamiento ${ }^{[54]}$.

La prevención general negativa en un proceso de justicia transicional es fundamental, pues de la seriedad de los mecanismos y de la efectiva condena de los responsables depende que no exista una repetición de las conductas por parte de otros grupos armados, o una reincidencia de los mismos autores de los crímenes. Sin embargo, esa condena puede consistir en penas alternativas orientadas a que tengan consecuencias positivas para toda la sociedad. 


\section{Prevención general positiva}

Finalmente, la prevención general positiva se relaciona con el restablecimiento de la confianza de los individuos en el ordenamiento jurídico, a través del fortalecimiento del Estado de Derecho, de la democracia y del desmantelamiento de organizaciones criminales ${ }^{[55]}$. En este aspecto, la existencia de un conflicto armado en una sociedad tiene tres efectos profundamente nocivos que deben ser eliminados si se espera reducir la criminalidad:

- La violencia institucionalizada hace que la fuerza se convierta en una forma de alcanzar poder ${ }^{[56]}$ y la superioridad sobre otros ${ }^{[57]}$, lo cual se canaliza a través de la agresividad como mecanismo de dominación de otras personas ${ }^{[58]}$, situación que cambia radicalmente los valores sociales, pues se crean verdaderas subculturas y contraculturas dominadas por la agresión ${ }^{[59]}$. Esta agresividad se va aprendiendo en la infancia como estereotipo y luego se desarrolla como forma de dominación ${ }^{[60]}$ generando actos que vulneran los derechos humanos y la dignidad humana que van generando actividades rutinarias criminales ${ }^{[61]}$. Esta situación tiene terribles efectos en el tejido social y también en la aplicación del Derecho penal, pues una violencia institucionalizada muta la cuestión criminal de una delincuencia de subsistencia a una criminalidad de poder mafiosa o terrorista, las cuales se apoderan de la economía y se convierten en un reclutador ilegal de la pequeña delincuencia, aprovechándose de la ignorancia, la miseria y el fanatismo ${ }^{[62]}$.

- La participación de la criminalidad organizada. El art. 1.1 del Protocolo Adicional II requiere para que exista un conflicto armado interno "la dirección de un mando responsable, ejerzan sobre una parte de dicho territorio un control tal que les permita realizar operaciones militares sostenidas y concertadas". Por su parte, el Estatuto de la Corte Penal internacional señala que "existe un conflicto armado prolongado entre las autoridades gubernamentales y grupos armados organizados o entre tales grupos" ${ }^{\text {[63] }}$. De esta manera, se exige que exista una política organizada relacionada con un comando central, una estructura jerárquica y la capacidad de realizar operaciones militares ${ }^{[64]}$. Por lo anterior, los conflictos armados exigen la participación de grupos organizados, los cuales, cuando cumplen determinadas características, constituyen parte de la criminalidad organizada. El crimen organizado es el conjunto de actividades de los miembros de una asociación altamente organizada y disciplinada que se dedicada a suministrar bienes y servicios ilegales ${ }^{[65]}$ y genera estructuras al interior de la sociedad que afectan el comportamiento de las personas.

- La cultura de la ilegalidad en los territorios afectados. Si bien el dominio territorial no es necesariamente considerado como un elemento del conflicto armado para efectos de la aplicación del Derecho Penal Internacional ${ }^{[66]}$, sí se exige en el artículo 1.2 del Protocolo Adicional II a los Acuerdos de Ginebra y también es frecuente en los grandes conflictos que se han presentado a nivel mundial. Esta situación crea verdaderas contraculturas en las cuales dominan los grupos armados, que se asientan en los grupos sociales reproduciendo este sistema por décadas a través del aprendizaje social, en el cual el modelo social recompensa la conducta imitativa (por ello los niños desarrollan un hábito generalizado de reproducir las respuestas de sucesivos modelos) y posteriormente las pautas de conducta aprendidas tienden a generalizarse a situaciones distintas de aquellas en que se aprendieron ${ }^{[67]}$. De esta manera, la ilegalidad se va volviendo una actividad casi rutinaria comenzando con delitos que causan daños a la persona o propiedad de otros ${ }^{[68]}$, que posteriormente se amplía a otros ámbitos como la corrupción ${ }^{[69]}$, debido a la perspectiva conjunta de esta teoría con la de la decisión racional ${ }^{[70]}$. En virtud de ello, la delincuencia en el conflicto armado está tan arraigada en 
la sociedad que es muy difícil de eliminar e incluso llega a multiplicarse en las cárceles a través de la aplicación del propio sistema penal.

Por lo anterior, el cumplimiento de esta función es uno de los retos más complejos, pues dependerá de que el Sistema Integral de Verdad, Justicia, Reparación y No Repetición, logre sus objetivos centrales consolidando la legitimidad de la justicia transicional.

\section{La retribución}

Elster analiza dos teorías relacionadas con la retribución: (i) las emociones retributivas que implican sentimientos como la ira, el desprecio, la indignación y el odio que la sociedad canaliza a través de leyes penales $^{[71]}$ y (ii) el merecimiento, el cual implica que los criminales merecen ser castigados por sus actos, con independencia de las consecuencias de castigarlos, y esto en la justicia transicional tiene dificultades tales como la complejidad de la determinación de la gravedad de los crímenes y de un sistema de penas acorde a estos $^{[72]}$. En una visión maximalista, la retribución constituye un obstáculo impenetrable a los juicios por las violaciones a los derechos humanos en los conflictos armados internos, pues estos crímenes se caracterizan porque son cometidos por muchas manos, en tanto que, por las realidades políticas y dificultades prácticas, la realización de juicios universales conlleva una impunidad extendida: todos deben ser castigados, por lo cual nadie lo es ${ }^{[73]}$.

La retribución también resulta esencial en los procesos de justicia transicional, pero no desde el punto de vista del castigo, sino desde la determinación del carácter injusto de una conducta, para el reconocimiento y la estigmatización del mal (wrongdoing) como un requisito esencial de toda sociedad en un proceso de transformación ${ }^{[74]}$.

El argumento internacional del deber de castigar se funda en varias normas convencionales y de costumbre, sin embargo, en ningún momento construye el castigo como un derecho ejecutable a través de una obligación de los Estados, pues incluso este deber se encuentra sujeto a alguna discrecionalidad en Estados democráticos, por lo cual las exigencias convencionales se han considerado satisfechas luego de otorgar alternativas. Así lo reconoció la Corte Interamericana de Derechos Humanos cuando en el caso Velásquez Rodríguez señaló que la obligación del Estado podría ser cumplida con el establecimiento de medidas remedios, investigaciones y reparaciones. Aun así, cuando evaluó las leyes de amnistía de Argentina y Uruguay consideró que los Estados vulneraron numerosos deberes de la Convención Americana de Derechos Humanos, entre ellos, el derecho de las víctimas a buscar justicia ${ }^{[75]}$. Dicho deber no puede confundirse con un derecho concreto de la víctima al castigo del ofensor, pues ello desnaturalizaría la función protectora y la naturaleza pública del derecho penal, pero sí permite que se manifieste la injusticia sufrida y se ofrezca una garantía de no repetición, de manera tal que se devuelve la confianza de la víctima en el ordenamiento y en la sociedad, y se favorece su no desocialización ${ }^{[76]}$.

En este sentido, como ya se indicó, una visión maximalista de la retribución tendría dificultades prácticas en la realización de juicios universales, por cuanto se genera una impunidad extendida: todos deben ser castigados, por lo cual nadie lo es ${ }^{[77]}$. En consecuencia, deben existir mecanismos especiales para que el procesamiento de las personas que sean enjuiciadas sea más efectivo, pues de lo contrario la sanción sería completamente selectiva y discrecional.

En este aspecto debe reconocerse que el contenido de las consecuencias contempladas en el sistema de la JEP no es netamente restaurativo, también tiene elementos retributivos concretos que pueden implicar la restricción de derechos de acuerdo a la consecuencia aplicable.

En el caso de las sanciones propias, el propio acuerdo final reconoce que deberán señalar establecer la restricción de derechos y libertades, lo cual es confirmado por la Ley 1957 de 2019 señala éstas “comprenderán 
restricciones efectivas de libertades y derechos, tales como la libertad de residencia y movimiento, que sean necesarias para su ejecución, y además deberán garantizar la no repetición" ${ }^{[78]}$. Adicionalmente, el propio cumplimiento de la actuación en favor de las comunidades implica per se la realización de labores específicas que exigen el tiempo y el compromiso de los comparecientes en horarios y condiciones especiales ${ }^{[79]}$. Frente a las sanciones alternativas la propia Ley 1957 de 2019 señala que "tendrán una función esencialmente retributiva de pena privativa de la libertad de cinco (5) a ocho (8) años" ${ }^{[80]}$. Finalmente, las sanciones ordinarias pueden tener una privación efectiva de la libertad de 15 a 20 años ${ }^{[81]}$.

\section{Efectos de una visión articulada de los objetivos de la justicia transicional con las funciones de la pena}

La aplicación de los objetivos de la justicia transicional de manera articulada con las funciones del Derecho penal no tiene un contenido netamente semántico, sino que tienen efectos particulares en todo el sistema para hacerlos compatibles dentro de los cuales se destacan los siguientes.

\section{El régimen de condicionalidad}

Existen múltiples mecanismos para lograr una transición que asegure la reconciliación y el establecimiento de una paz estable y duradera. Por ello, resultan esenciales los instrumentos que garanticen la prevención especial que impidan que los comparecientes del sistema vuelvan a cometer delitos y, a la vez, garanticen su resocialización. En este marco tiene especial importancia la consagración de un régimen de condicionalidad que permita asegurar que los comparecientes cumplan con sus obligaciones y especialmente no vuelvan a las armas.

En este sentido, en el inciso $5^{\circ}$ del artículo transitorio $1^{\circ}$ del Acto Legislativo 01 de 2017 se establece que los mecanismos del sistema "estarán interconectados a través de relaciones de condicionalidad y de incentivos para acceder y mantener cualquier tratamiento especial de justicia, siempre fundados en el reconocimiento de verdad y responsabilidades". En desarrollo de esta norma, el inciso $8^{\circ}$ del artículo transitorio $5^{\circ}$ del Acto legislativo 01 de 2017 vincula el tratamiento especial de justicia al cumplimiento de las obligaciones de aportar verdad plena, reparar a las víctimas y garantizar la no repetición y señala que quienes aporten dolosamente información falsa o incumplan cualquiera de las condiciones del Sistema, lo perderán.

Por lo anterior, la Corte Constitucional ha señalado que en virtud del régimen de condicionalidad del SIVJRNR "se somete el tratamiento penal especial a los deberes de aportar verdad plena, reparar a las víctimas y garantizar la no repetición" ${ }^{[82]}$ y por ello "todo beneficio se somete a que la persona reconozca verdad completa, detallada y exhaustiva, y satisfaga los derechos de las víctimas a la reparación y a la no repetición"[83]. El alcance de estas obligaciones se estableció concretamente en el artículo 20 de la Ley 1957 de 2019:(i) la obligación de aportar verdad plena implica aportar información, cuando se conozca de ella, sobre los crímenes de competencia de la JEP y respecto de los bienes adquiridos de manera ilegal y de quienes hayan prestado su nombre para adquirirlos, tenerlos, administrarlos y poseerlos, (ii) la obligación de garantizar la no repetición implica abstenerse de cometer nuevos delitos dolosos cuya pena mínima de prisión sea igual o superior a 4 años respecto de un listado específico de bienes jurídicos ${ }^{[84]}$ y (iii) contribuir a la reparación de las víctimas, y en particular, manifestar la verdad en relación con los procedimientos y protocolos para inventariar todo tipo de bienes y activos. Adicionalmente, en el caso de los desmovilizados de las FARC-EP, también se debe garantizar el cumplimiento de las siguientes obligaciones: “(a) la dejación de armas, b) obligación de 
contribuir activamente a garantizar el éxito del proceso de reincorporación a la vida civil de forma integral y (c) la entrega de menores de edad".

En todo caso, las consecuencias de la infracción del régimen de condicionalidad deberán ser proporcionales a la gravedad del incumplimiento ${ }^{[85]}$, pues pueden implicar desde la pérdida de beneficios como la libertad condicionada, como sucedió inicialmente en el caso de Hernán Darío Velásquez ${ }^{[86]}$ hasta la expulsión de la JEP, como sucedió en el caso de Iván Márquez Marín, José Manuel Sierra y Henry Castellanos ${ }^{[87]}$.

Particularmente, el caso de la expulsión de la JEP solamente se puede presentar de manera excepcional "cuando se incumple la condición básica de no repetición, abandonando el proceso de paz para alzarse nuevamente en armas, cuando se aporta de manera dolosa información falsa o se incumplan las demás condiciones del sistema, según lo decida la JEP conforme a los principios de proporcionalidad y gradualidad, incluso en cuando se trate de otros actores responsables de hechos de competencia de la jurisdicción" ${ }^{[88]}$.

En este sentido, tanto la Corte Constitucional ${ }^{[89]}$, como la Sección de Apelación de la JEP han considerado que el compromiso de no repetición consistente en no alzarse nuevamente en armas contra el Estado, ni integrar grupos armados organizados constituye

un requisito esencial para acceder a la JEP y para obtener y mantener los beneficios, tratamientos especiales, derechos y garantías previstos en el ordenamiento transicional. Es, además, un requisito de permanencia, pues debe ser cumplido de manera continua por todos los exintegrantes de las FARC-EP. ${ }^{[90]}$

En este particular, la Sección de Apelación ha sido clara en señalar que "la deserción armada manifiesta del proceso de paz equivale a una autoexclusión de la jurisdicción transicional por su carácter voluntario, público e inequívoco" ${ }^{\text {[91]. }}$.

Sin embargo, este sistema no estaría completo sin una herramienta procesal para poder decidir sobre las infracciones a este régimen que está contemplado en el inciso primero del artículo 67 de las Reglas de Procedimiento (Ley 1922 de 2018) que creo el incidente de incumplimiento:

Artículo 67. Incidente de incumplimiento. Las Salas y Secciones harán seguimiento al cumplimiento del Régimen de Condicionalidad y a las sanciones que hayan impuesto en sus resoluciones o sentencias.

Este incidente tiene por objeto que se garanticen plenamente no solamente los derechos de las víctimas, sino también la seguridad jurídica de todas las personas que estén sometidas a la JEP, a través de un procedimiento en el cual se decreten y practiquen pruebas sobre el presunto incumplimiento y se pueda ejercer plenamente el derecho a la defensa. Este incidente puede ser iniciado de oficio por los Magistrados de las Salas y Secciones de la JEP o por solicitud de la víctima, su representante, el Ministerio Público, la Fiscalía General de la Nación o la UIA, tal como dispone el inciso segundo del artículo 67 de la Ley 1922 de 2018:

De oficio, por solicitud de la víctima, su representante, el Ministerio Público, la Fiscalía General de la Nación o la UIA, las Salas y Secciones podrán ordenar la apertura del incidente de incumplimiento del Régimen de Condicionalidad, del cual será notificada la persona sometida a la JEP, a su defensor, a las víctimas, a su representante y al Ministerio Público. En la misma decisión se dispondrá un traslado común de cinco (5) días para que los notificados soliciten o alleguen pruebas. Vencido el término la Sala o Sección decretará las pruebas pertinentes, útiles y necesarias, y podrá además decretar pruebas de oficio con el objeto de verificar de manera rigurosa el cumplimiento del Régimen de Condicionalidad o de la sanción, para lo cual podrá comisionar a la UIA por un término que no supere treinta (30) días, en el cual también serán practicadas las pruebas solicitadas por los sujetos procesales e intervinientes.

A partir de este sistema se presenta una interesante conjunción de la función preventiva especial de la pena con la garantía de no repetición propia de un sistema de justicia transicional que asegura el debido proceso a través de un incidente en el que se debe salvaguardar el derecho a la defensa. 


\section{Régimen de sanciones propias}

El Acuerdo Final para la Terminación del Conflicto y la Construcción de una Paz Estable y Duradera establece que la finalidad esencial de las sanciones que se impongan dentro del Sistema Integral de Verdad Justicia Reparación y Garantías de No Repetición debe ser la satisfacción de los derechos de las víctimas y la consolidación de la paz, para lo cual debe primar la función retributiva y reparadora del daño causado, atendiendo al grado de reconocimiento de verdad y responsabilidad. En efecto, el punto 60 del Acuerdo Final señala que este tipo de sanciones comprenderán restricciones efectivas de libertades y derechos, tales como la libertad de residencia y movimiento que sean necesarias para su ejecución, y además deberán garantizar la no repetición. El artículo 13 del Acto legislativo 01 de 2017 reitera la finalidad expuesta por las sanciones y remite al contenido del citado acuerdo para referir las clases en que se pueden dar y su contenido:

Sanciones. Las sanciones que imponga la JEP tendrán como finalidad esencial satisfacer los derechos de las víctimas y consolidar la paz. Deberán tener la mayor función restaurativa y reparadora del daño causado, siempre en relación con el grado de reconocimiento de verdad y responsabilidad. Las sanciones podrán ser propias, alternativas u ordinarias y en todos los casos se impondrán en los términos previstos en los numerales 60, 61, 62 y en el listado de sanciones del subpunto 5.1.2 del Acuerdo Final.

Estas sanciones son aplicables respecto a aquellas personas que reconozcan la verdad exhaustiva, detallada y plena ante la JEP. Se contemplan tres tipos de sanciones, especialmente relacionadas con la participación en programas de reparación colectiva:

- En las zonas rurales se contemplan las siguientes: (i) participación o ejecución en programas de reparación efectiva para los campesinos desplazados; (ii) participación o ejecución de programas de protección medio ambiental de zonas de reserva; (iii) participación o ejecución de programas de construcción y reparación de infraestructuras en zonas rurales: escuelas, carreteras, centros de salud, viviendas, centros comunitarios, infraestructuras de municipios, etc.; (iv) participación o ejecución de programas de desarrollo rural; (v) participación o ejecución de programas de eliminación de residuos en las zonas necesitadas de ello; (vi) participación o ejecución de programas de mejora de la electrificación y conectividad en comunicaciones de las zonas agrícolas; (vii) participación o ejecución en programas de sustitución de cultivos de uso ilícito; (viii) participación o ejecución en programas de recuperación ambiental de las áreas afectadas por cultivos de uso ilícito; (ix) participación o ejecución de programas de construcción y mejora de las infraestructuras viales necesarias para la comercialización de productos agrícolas de zonas de sustitución de cultivos de uso ilícito.

- En zonas urbanas se contemplan las siguientes: (i) participación o ejecución de programas de construcción y reparación de infraestructuras en zonas urbanas: escuelas, vías públicas, centros de salud, viviendas, centros comunitarios, infraestructuras de municipios, etc.; (ii) participación o ejecución de programas de desarrollo urbano; y (iii) participación o ejecución de programas de acceso a agua potable y construcción de redes y sistemas de saneamiento.

- Adicionalmente, también se incluyen tareas de limpieza y erradicación de restos explosivos de guerra: (i) participación o ejecución de programas de limpieza y erradicación de restos explosivos de guerra y municiones sin explotar; y (ii) participación o ejecución de programas de limpieza y erradicación de minas antipersona y artefactos explosivos improvisados.

Respecto de la dosificación de la sanción, la Ley Estatutaria de la JEP (1957 de 2019) señala que deben ser tenidos en cuenta los siguientes criterios: (i) El grado de verdad otorgado y su prontitud, (ii) la gravedad de la conducta sancionada, (iii) el nivel de participación y responsabilidad, las circunstancias de mayor y menor punibilidad, y (iv) los compromisos en materia de reparación a las víctimas y garantías de no repetición. 


\section{La consagración de un régimen sancionatorio especial para los menos responsables}

El sistema del marco jurídico para la paz, refrendado posteriormente en el Acto Legislativo 01 de 2017 y en las sentencias C-579 de 2013 y C-080 de 2018, centra la investigación, el juzgamiento y la sanción en los máximos responsables, lo cual puede implicar que aquellas personas que no cumplan esa condición se aplique una renuncia a la persecución penal. Esta situación fue analizada en la Corte Constitucional en la sentencia C-579 de 2013 y se funda no solo en el objetivo de lograr una paz estable y duradera sino también en la necesidad de tener en cuenta la relevancia de la conducta de los máximos responsables en crímenes que impliquen contextos de macrocriminalidad.

Esta situación hace que, efectivamente, se deban tener en cuenta circunstancias relacionadas con el conflicto sobre la individualización de la sanción, como una situación prolongada de violencia, la participación de la criminalidad organizada y la cultura de la ilegalidad en los territorios afectados, que hace que gran parte de las personas que participaron en el conflicto que nunca tuvieron la calidad de máximos responsables hayan sido reclutados de manera ilegal y hayan actuado como meros instrumentos de quienes realmente dirigieron las acciones en el conflicto armado.

\section{Conclusiones}

Pese a la actitud escéptica de gran parte de la doctrina sobre la función del derecho penal en los procesos de justicia transicional, las funciones de la pena están profundamente relacionadas con los objetivos de las transiciones. Alcanzar una transición que asegure la reconciliación y el establecimiento de una paz está profundamente relacionado con la finalidad de prevención, mientras que el objetivo de tratar con el pasado implica un componente retributivo que comienza con el enjuiciar el mal en sí mismo (wrongdoing).

Sin embargo, para poder generar un sistema efectivo que permita alcanzar estos objetivos es necesario contar con mecanismos que enlacen directamente el cumplimiento de las metas de la justicia transicional con consecuencias penales específicas, para lo cual existen por lo menos tres herramientas concretas:

El régimen de condicionalidad está directamente conectado con las obligaciones del sistema y dentro de ellas de manera particular con la no repetición que a su vez está relacionada con la prevención negativa. En casos concretos, la JEP ha aplicado esta herramienta al punto de incluso llegar a excluir del sistema a quienes vuelvan a las armas.

Las sanciones propias buscan no solamente garantizar una reconciliación a través de la restauración, sino que también están directamente conectadas con la prevención especial positiva a través del trabajo con las comunidades.

Finalmente, la diferenciación entre máximos y menos responsables permite que, cumpliendo los compromisos del Acuerdo y bajo un régimen de condicionalidad estricto, personas que no hayan tenido una participación definitiva en los crímenes y que hayan actuado más influenciados por la cultura de la ilegalidad en los territorios puedan reincorporarse más rápidamente a la sociedad.

\section{Bibliografía}

Agata Fijalkowski, Truth and reconciliation commissions, en An Introduction of transitional justice (Olivera Simić, ed., Routledge, 2017). https://doi.org/10.4324/9781315672649-5

Albert Bandura \& Richard Walters, Aprendizaje social y desarrollo de la personalidad (Alianza Editorial, 1990).

Alfred Adler, Práctica y teoría de la psicología del individuo (Paidós, 1958). 
Alicia Gil, Sobre la satisfacción de la víctima como fin de la pena, Indret: Revista para el Análisis del Derecho, n. 0 , 1-39 (2016).

Ana Messuti, La justicia deconstruida (2008).

Anja Mirh, An Introduction to Transitional Justice, en An Introduction of Transitional Justice (Simic, Olivera ed., Routledge, 2017). https://doi.org/10.4324/9781315672649-1

Camila De Gamboa Tapias, La transición democrática y la responsabilidad de la comunidad por su pasado, en Justicia transicional. Teoría y praxis (Camila De Gamboa Tapias ed., 2006).

Carlos Nino, Juicio al mal absoluto (2006).

Claus Roxin, Derecho penal: parte general (1997).

Colleen Murphy, Transitional Justice, Retributive Justice and Accountability for wrongdoing, en Theorizing Transitional Justice (Claudio Corradetti \& Nir Eisikovits \& Jack Volpe Rotondi eds., 2014).

Corte Constitucional de Colombia. Sentencia C-080 de 2018 (M. P. Antonio José Lizarazo Ocampo; 15 de agosto de 2018).

Corte Constitucional de Colombia. Sentencia C-674 de 2017(M. P. Luis Guillermo Guerrero Pérez; 14 de noviembre de 2017).

Corte Constitucional de Colombia. Sentencia C-806 de 2002 (M. P. Clara Inés Vargas Hernández; 3 de octubre de 2002).

David C. McClelland, Estudio de la motivación humana (Narcea, 1989).

Derek B. Cornish \& Ronald Clarke, Introduction, en The Reasoning Criminal: Rational Choice Perspectives on Offending, (Derek B. Cornish \& Ronald Clarke, eds., Transaction Publishers, 1986).

Erling Eide, Economics of Crime. Deterrence and the Rational Offender, North-Holland, Amsterdam (Emerald Publishing,1994). https://doi.org/10.1108/S0573-8555(1994)227

Francisco Muñoz Conde \& Mercedes García Aran, Derecho penal: parte general (Tirant lo Banch, 2007).

Gabriele Fornasari, Giustizia di transizione e Diritto Penale (2013).

Guillermo O'donnell \& Phillipe Schmitter, Transitions for authoritarian Rule, en Transitional Justice (Neil Kritz ed., United States Institute of Peace Press, 1995).

Hans Heinrich Jescheck \& Thomas Weigend, Tratado de derecho penal: parte general (Comares, 2002).

I Kai Ambos, Treatise on International Criminal Law: Foundations and General Part (2013).

Ignacio Martín Baró, Poder, ideología y violencia (Trotta, 2003).

II Franz Liszt, Tratado de derecho penal (1916).

Isidoro Blanco Cordero, La corrupción desde una perspectiva criminológica: un estudio de sus causas desde las teorías de las actividades rutinarias y de la elección racional, en Serta; In memoriam Alexandri Baratta (Fernando Pérez Álvarez, coord., Ediciones Universidad de Salamanca, 2004).

Jaime Malamud-Goti, Lo bueno y lo malo de la inculpación y las víctimas, en Justicia transicional. Teoría y praxis (Camila De Gamboa Tapias ed., 2006).

James Finkenauer, Mafia y crimen organizado (One-world publications, 2010).

JEP, Sala de Reconocimiento de Verdad, de Responsabilidad y de Determinación de los Hechos y Conductas, Auto 061, 26 de abril de 2019.

Jesús María Silva Sánchez, Malum Passionis. Mitigar el dolor del Derecho penal (Atelier, 2018).

Jon Elster, Closing the books, (Cambridge University Press, 2004). https://doi.org/10.1017/CBO9780511607011

Jon Elster, Justice, Truth, Peace, en Transitional Justice (Melissa Williams, Rosemary Nagy \& Jon Elster, 2012).

Jon Elster, Retribution, en Retribution and Reparation in the Transition to Democracy (Jon Elster, ed., Cambridge University Press, 2006). https://doi.org/10.1017/CBO9780511584343

Jurisdicción Especial para la Paz (JEP), Sala de Reconocimiento de Verdad, de Responsabilidad y de Determinación de los Hechos y Conductas, Auto 216, 4 de octubre de 2019. 
Jurisdicción Especial para la Paz (JEP), Sección de Apelación, Auto TP-SA 288 de 2019, 13 de septiembre de 2019.

Lawrence Cohen \& Marcus Felson, Social change and crime rate trends: a routine activity approach, 44 American Social Review, n. ${ }^{\circ} 44,588-608$ (1979). https://doi.org/10.2307/2094589

Ley 1922 de 2018. Por medio de la cual se adoptan unas reglas de procedimiento para la Jurisdicción Especial para la Paz. 18 de julio de 2018. D. O. 50.658.

Ley 1957 de 2019. Estatutaria de la Administración de Justicia en la Jurisdicción Especial para la Paz. 6 de junio 2019. D. O. 50.976.

Luigi Ferrajoli, La justicia penal transicional para Colombia del posconflicto y las garantías para la paz interna, en Justicia, derecho y posconflicto en Colombia (Londoño Ulloa \& Jorge Eduardo eds., 2016)

Luigi Ferrajoli, Principia iuris. Teoría del derecho y de la democracia (Trotta Editorial, 2007).

Luis Guillermo Guerrero Pérez, Justicia transicional en el derecho comparado, en Diálogo constitucional para la paz. IX conversatorio de la Jurisdicción Constitucional, 18 al 20 de septiembre de 2013, Medellín, Colombia (Jorge Iván Palacio et al. eds., 2014).

Michael A. Hogg \& Graham M. Vaughan, Psicologia social (Editorial Médica Panamericana, 2010).

Neil Kritz, The Dilemas of Transitional Justice, en Transitional Justice (United States Institute of Peace Press, 1995).

Rafael Guarín, Los derechos de las víctimas límite a la paz, 18 Revista Nueva Época, n. ${ }^{\circ} 39$ (2012).

Melissa Williams, Rosmery Nagy \& Jon Elster, Transitional Justice (New York University Press, 2002).

Rodrigo Uprimny Yepes, Las enseñanzas del análisis comparado: Procesos transicionales, formas de justicia transicional y el caso colombiano, en ¿justicia transicional sin transición? Verdad, justicia y reparación para Colombia (Rodrigo Uprimny Yepes, María Paula Saffon Sanín, Catalina Botero Marino, \& Esteban Restrepo Saldarriaga eds., 2006).

Ronald Clarke, \& Marcus Felson, Routine Activity and Rational Choice. Advances in Criminological Theory (Transaction Publishers, 1993).

Ruti G. Teitel, Trasitional Justice (Oxford University Press, 2000).

Santiago Mir Puig, Derecho penal: parte general (Reppertor, 2011).

Stephen Worchel, Joel Cooper, George R. Goethals, James M. Olson, Psicología Social (Ed. Paraninfo, 2002).

Susanne Beckeley-Zistel, On the Construction of the Past in Truth Comissions, en, Transitional Justice Theories: Transitional Justice Theories (Susanne Buckeley-Zistel, Teresa Koloma Beck, Christian Braun, Friederike Mieth eds., 2014).

\section{Notas}

[1] Ruti G. Teitel, Trasitional Justice (Oxford University Press, 2000).

[2] Neil Kritz, The dilemas of transitional justice, en Transitional Justice, 21 (United States Institute of Peace Press, 1995); Rodrigo Uprimny Yepes, Las enseñanzas del análisis comparado: Procesos transicionales, formas de justicia transicional y el caso colombiano, en ¿Justicia transicional sin transición? Verdad, justicia y reparación para Colombia, 13 (Rodrigo Uprimny Yepes, María Paula Saffon Sanín, Catalina Botero Marino, \& Esteban Restrepo Saldarriaga eds., 2006); Luis Guillermo Guerrero Pérez, Justicia transicional en el derecho comparado, en Diálogo constitucional para la paz. IX conversatorio de la Jurisdicción Constitucional, 18 al 20 de septiembre de 2013, Medellín, Colombia, 104 (Jorge Iván Palacio et al. eds., 2014); Anja Mirh, An Introduction to Transitional Justice, en An Introduction of Transitional Justice, 1 (Simic, Olivera ed., Routledge, 2017).

[3] Ruti G. Teitel, op. cit.,29 y 30.

[4] Íd., 50.

[5] Luigi Ferrajoli, La justicia penal transicional para Colombia del posconflicto y las garantías para la paz interna, en Justicia, derecho y posconflicto en Colombia, 25 (Londoño Ulloa \& Jorge Eduardo eds., 2016).

[6] Art. 1 de la Ley 1922 de 2018.

[7] Aunque cabe resaltar que algunos como Uprimny Yepes plantean la posibilidad de aplicar sus medidas, aunque no exista transición lo cierto es que el mismo concepto exige este requisito (Cfr. Rodrigo Uprimny Yepes, op. cit.

[8] Ruti G. Teitel, op. cit.,29 y 30. 
[9] Neil Kritz, The dilemas of transitional justice, op. cit., 21; Rodrigo Uprimny Yepes, op. cit., 13; Anja Mirh, op. cit., 1.

[10] Artículo $1^{\circ}$ de la Ley 1922 de 2018.

[11] Jaime Malamud-Goti, Lo bueno y lo malo de la inculpación y las víctimas, en Justicia transicional. Teoría y praxis, 158-159 (Camila De Gamboa Tapias ed., 2006); Camila De Gamboa Tapias, La transición democrática y la responsabilidad de la comunidad por su pasado, en Justicia transicional. Teoría y praxis, 150 (Camila De Gamboa Tapias ed., 2006); Jon Elster, Justice, Truth, Peace, en Transitional Justice, 88 (Melissa Williams, Rosemary Nagy \& Jon Elster, 2012).

[12] Jaime Malamud-Goti, op. cit., 158-159; Jon Elster, op. cit., 77-78; Camila De Gamboa Tapias, op. cit., 150.

[13] Luigi Ferrajoli, La justicia penal transicional para Colombia del posconflicto y las garantías para la paz interna, op. cit., 23.

[14] Íd.,24.

[15] Art. 20 de la Ley 1957 de 2019.

[16] JEP, Sala de Reconocimiento de Verdad, de Responsabilidad y de Determinación de los Hechos y Conductas, Auto 061, 26 de abril de 2019.

[17] Corte Constitucional de Colombia. Sentencia C-080 de 2018 (M. P. Antonio José Lizarazo Ocampo; 15 de agosto de 2018).

[18] Neil Kritz, The dilemmas of transitional justice, op. cit., 21-30; Guillermo O'donnell \& Phillipe Schmitter, Transitions for authoritarian Rule, en Transitional Justice (Neil Kritz ed., United States Institute of Peace Press, 1995); Gabriele Fornasari, Giustizia di transizione e Diritto Penale, 4 (2013).; Agata Fijalkowski, Truth and reconciliation commissions, en An Introduction of transitional justice, 94 (Olivera Simić, ed., Routledge, 2017); Anja Mirh, op. cit., 2; Colleen Murphy, Transitional Justice, Retributive Justice and Accountability for wrongdoing, en Theorizing Transitional Justice, 182-186 (Claudio Corradetti \& Nir Eisikovits \& Jack Volpe Rotondi eds., 2014).

[19] Ruti G. Teitel, op. cit.,29 y 30.

[20] Íd., 50.

[21] Íd., 69.

[22] Susanne Beckeley-Zistel, On the Construction of the Past in Truth Comissions, en, Transitional Justice Theories: Transitional Justice Theories, 145 (Susanne Buckeley-Zistel, Teresa Koloma Beck, Christian Braun, Friederike Mieth eds., 2014).

[23] Ana Messuti, La justicia deconstruida, 245 (2008).

[24] Luigi Ferrajoli, La justicia penal transicional para Colombia del posconflicto y las garantías para la paz interna, op. cit., 28.

[25] Íd., 27.

[26] Rafael Guarín, Los derechos de las víctimas límite a la paz, 18 Revista Nueva Época, n. ${ }^{\circ}$ 39, 142 (2012).

[27] Art. 1 de la Ley 1922 de 2018

[28] Artículo 11 de la Ley 1922 de 2018.

[29] Corte Constitucional de Colombia. Sentencia C-080 de 2018 (M. P. Antonio José Lizarazo Ocampo; 15 de agosto de 2018).

[30] Neil Kritz, The dilemas of transitional justice, op. cit., 14; Melissa Williams, Rosmery Nagy \& Jon Elster, Transitional Justice, 5 (New York University Press, 2002); Jon Elster, Closing the books, 3 y ss. (Cambridge University Press, 2004)

[31] Jon Elster, op. cit., 88.

[32] Jesús María Silva Sánchez, Malum Passionis. Mitigar el dolor del Derecho penal, 82 y ss. (Atelier, 2018).

[33] Gabriele Fornasari, op. cit., 202-207.

[34] Literal d.

[35] Literal e.

[36] Literal f.

[37] Art. 35.

[38] Art. 28.

[39] Art. 12.

[40] Art. 13.

[41] Art. 14.

[42] Art. 19.

[43] II Franz Liszt, Tratado de derecho penal, 10 (1916). Claus Roxin, Derecho penal: parte general, 85 (1997); Hans Heinrich Jescheck \& Thomas Weigend, Tratado de derecho penal: parte general (Comares, 2002); Francisco Muñoz Conde \& Mercedes García Aran, Derecho penal: parte general, 48 (Tirant lo Banch, 2007); Santiago Mir Puig, Derecho penal: parte general, 84 (Reppertor, 2011).

[44] La prevención especial negativa señala que la pena puede tener también como misión impedir que el delincuente cometa nuevos crímenes contra la sociedad.

[45] Art. 62 de la Ley 1957 de 2019.

[46] Corte Constitucional de Colombia. Sentencia C-080 de 2018 (M. P. Antonio José Lizarazo Ocampo; 15 de agosto de 2018). 
[47] Jon Elster, Retribution, en Retribution and Reparation in the Transition to Democracy, 52-53 (Jon Elster, ed., Cambridge University Press, 2006).

[48] Franz Liszt, op. cit., 10; Claus Roxin, op. cit., 87; Hans Heinrich Jescheck \& Thomas Weigend, op. cit., 5; Francisco Muñoz Conde \& Mercedes García Aran, op. cit., 48; Santiago Mir Puig, op. cit., 84.

[49] Derek B. Cornish \& Ronald Clarke, Introduction, en The Reasoning Criminal: Rational Choice Perspectives on Offending, 1-4 (Derek B. Cornish \& Ronald Clarke, eds., Transaction Publishers, 1986); Ronald Clarke \& Marcus Felson, Routine Activity and Rational Choice. Advances in Criminological Theory, 4 (Transaction Publishers, 1993); Erling Eide, Economics of Crime. Deterrence and the Rational Offender, North-Holland, Amsterdam, 9 y ss. (Emerald Publishing, 1994).

[50] Jon Elster, Retribution, op. cit., 51.

[51] Derek B. Cornish \& Ronald Clarke, op. cit., 20.

[52] Art. 142 de la Ley 1957 de 2019.

[53] Jon Elster, Retribution, op. cit., 49.

[54] Î́d., 50.

[55] Para la prevención general positiva, la finalidad de la pena es el reconocimiento de la norma, con el objeto de restablecer su vigencia, afectada por el delito, y mantener las estructuras necesarias de una sociedad. Corte Constitucional de Colombia. Sentencia C-806 de 2002 (M. P. Clara Inés Vargas Hernández; 3 de octubre de 2002).

[56] David C. McClelland, Estudio de la motivación humana, 289 (Narcea, 1989).

[57] Alfred Adler, Práctica y teoría de la psicología del individuo, 58 (Paidós, 1958).

[58] Stephen Worchel, Joel Cooper, George R. Goethals, James M. Olson, Psicología Social, 208-209 (Ed. Paraninfo, 2002); Michael A. Hogg \& Graham M. Vaughan, Psicologia social, 350 (Editorial Médica Panamericana, 2010).

[59] Ignacio Martín Baró, Poder, ideología y violencia, 86 (Trotta, 2003).

[60] Stephen Worchel, Joel Cooper, George R. Goethals, James M. Olson, op. cit., 208-210.

[61] Lawrence Cohen \& Marcus Felson, Social change and crime rate trends: a routine activity approach, 44 American Social Review, n. 44,589 (1979).

[62] Luigi Ferrajoli, Principia iuris. Teoría del derecho y de la democracia, 353 (Trotta Editorial, 2007).

[63] Art. 8.2, literal f) del Tratado de la Corte Penal Internacional.

[64] I Kai Ambos, Treatise on International Criminal Law: Foundations and General Part (2013).

[65] James Finkenauer, Mafia y crimen organizado, 26 (One-world publications, 2010).

[66] Ambos, Kai, op. cit., p. 128.

[67] Albert Bandura \& Richard Walters, Aprendizaje social y desarrollo de la personalidad, 18-21 (Alianza Editorial, 1990).

[68] Lawrence Cohen \& Marcus Felson, op. cit., 589.

[69] Isidoro Blanco Cordero, La corrupción desde una perspectiva criminológica: un estudio de sus causas desde las teorías de las actividades rutinarias y de la elección racional, en Serta; In memoriam Alexandri Baratta, 274 (Fernando Pérez Álvarez, coord., Ediciones Universidad de Salamanca, 2004).

[70] Sobre la aplicación de ambas teorías a ámbitos como el crimen organizado, los delitos en el tráfico y el secuestro ver: Ronald Clarke \& Marcus Felson, op. cit., 37 y ss.; Isidoro Blanco Cordero, op. cit., 274.

[71] Jon Elster, Retribution, op. cit., 37.

[72] Î́d., 47 - 48.

[73] Carlos Nino, Juicio al mal absoluto, 258 (2006).

[74] Î́d., 50.

[75] Ruti G. Teitel, op. cit.,55.

[76] Alicia Gil, Sobre la satisfacción de la víctima como fin de la pena, Indret: Revista para el Análisis del Derecho, n. ${ }^{\circ}$ 4, 31 (2016).

[77] Carlos Nino, op. cit., 258.

[78] Art. 127 de la Ley 1957 de 2019.

[79] Íd.

[80] Art. 128 de la Ley 1957 de 2019.

[81] Art. 130 de la Ley 1957 de 2019.

[82] Corte Constitucional de Colombia. Sentencia C-674 de 2017(M. P. Luis Guillermo Guerrero Pérez; 14 de noviembre de 2017).

[83] Íd.

[84] La vida e integridad personal; personas y bienes protegidos por el $\mathrm{DIH}$; libertad individual y otras garantías; la libertad, integridad y formación sexuales; el orden económico y social; los recursos naturales y el medio ambiente; la seguridad pública; la salud pública; los mecanismos de participación democrática; la administración pública; la eficaz y recta administración de justicia; la existencia y seguridad del Estado; el régimen constitucional y legal, así como el delito de extorsión, o delitos de ejecución permanente. 
[85] Corte Constitucional de Colombia. Sentencia C-080 de 2018 (M. P. Antonio José Lizarazo Ocampo; 15 de agosto de 2018).

[86] JEP, Sala de Reconocimiento de Verdad, de Responsabilidad y de Determinación de los Hechos y Conductas, Auto 061, 26 de abril de 2019.

[87] JEP, Sala de Reconocimiento de Verdad, de Responsabilidad y de Determinación de los Hechos y Conductas, Auto 216, 4 de octubre de 2019.

[88] Corte Constitucional de Colombia. Sentencia C-080 de 2018 (M. P. Antonio José Lizarazo Ocampo; 15 de agosto de 2018).

[89] Corte Constitucional de Colombia. Sentencia C-080 de 2018 (M. P. Antonio José Lizarazo Ocampo; 15 de agosto de 2018).

[90] JEP, Sección de Apelación, Auto TP-SA 288 de 2019, 13 de septiembre de 2019, 20-21.

[91] JEP, Sección de Apelación, Auto TP-SA 288 de 2019, 13 de septiembre de 2019, 12.

* Artículo de reflexión

\section{Licencia Creative Commons CC BY 4.0}

Cómo citar este artículo: Carlos Guillermo Castro Cuenca, Las funciones del derecho penal y de la justicia transicional en la jurisdicción especial para la paz, 69 Vniversitas (2020). https://doi.org/10.11144/Javerian a.vj69.fdpj 